\title{
How to design a digital storytelling authoring tool for developing pre-reading and pre-writing skills
}

\author{
Elisa Rubegni \\ University of Lincoln, School of \\ Computer Science \\ Lincoln, UK \\ erubegni@lincoln.ac.uk
}

\author{
Monica Landoni \\ Università della Svizzera \\ italiana \\ Lugano, Switzerland \\ monica.landoni@usi.ch
}

\begin{abstract}
In the paper we describe an exploration into the design of an authoring tool to support the creation of multimedia stories. We explicitly targeted children with no reading or writing skills and their educators. Children in this age group often enjoy reading and creating stories together with adults and in so doing develop important pre-literacy skills. Literature suggests that when children play an active role in these activities, with a high level of engagement and interaction, there is a significant increase in their vocabulary acquisition and an improvement in their communication skills. Thus, we investigated these issues by conducting an explorative study in a pre-school class with fifteen children and three teachers. Here, we describe the emerging challenges and provide design directions for an authoring system to support the co-creation of stories for pre-literate children.
\end{abstract}

\section{Author Keywords}

Digital storytelling; pre-school; co-reading; co-writing; preliterate children.

\section{ACM Classification Keywords}

H.5.m. Information interfaces and presentation (e.g., HCI): Miscellaneous;

\section{INTRODUCTION}

This research study is a spin-off of a previous project named PADS [11]. In project PADS we investigated whether technology could support educational activities in primary school according to the curriculum. In particular, we designed and developed an authoring tool called Fiabot! that allows primary school children to create multimedia fairy-tales. The encouraging results [12] showed how this tool was supporting the achievement of curricular objectives (improving reading, writing abilities, language and communication skills), and was easily adopted within a

Permission to make digital or hard copies of all or part of this work for personal or classroom use is granted without fee provided that copies are not made or distributed for profit or commercial advantage and that copies bear this notice and the full citation on the first page. Copyrights for components of this work owned by others than the author(s) must be honored. Abstracting with credit is permitted. To copy otherwise, or republish, to post on servers or to redistribute to lists, requires prior specific permission and/or a fee. Request permissions from Permissions@acm.org.

CHI 2018, April 21-26, 2018, Montreal, QC, Canada (C) 2018 Copyright is held by the owner/author(s). Publication rights licensed to ACM.

ACM 978-1-4503-5620-6/18/04 ..\$15.00

https://doi.org/10.1145/3173574.3173969 primary school context. Considering this previous experience, we decided to add a challenge to our research and to investigate whether this kind of tool could be used with pre-literate children.

In particular, we are interested in understanding how an authoring system can be designed in order to support preliterate children in co-creating a multimedia story with the educational goal of improving their pre-reading and writing skills. Our research contributes to the HCI and Children-Computer Interaction communities by highlighting four main challenges emerged in a pilot study run in a school with pre-literate children and their teachers.

In what follows we report briefly on the scholarly works in this area in order to delineate the space of our research.

\section{LITERATURE REVIEW}

Our theoretical approach in understanding and designing digital storytelling is grounded on a framework namely Narrative Activity Model (NAM) [9]. Based on Vygotsky's cycle of imagination [21], NAM articulates narrative creation in four main stages: exploration, inspiration, production and sharing. Therefore, during exploration, pupils have a direct or mediated (by social relations or tools) interaction with the environment (e.g. a field trip, a book, or a movie). The input gathered in the experience is later elaborated on in the narrative process. The inspiration phase is the moment in which children can understand the different aspects of their experience and dissociate from it. In this phase, they can analyze and reflect upon what they have experienced by producing new content. The production phase corresponds to the association process: children externalize the product of their imagination and express their emotions by creating the plot and the characters. The story can take different forms, e.g. written text, drawings, and/or speech. The fourth phase is sharing and it can be done in different ways, for example verbally by reading or acting and be enhanced with other elements such as music. This last phase concludes the cycle. This model has been successfully applied to build tools to support narrative creations $[9,11]$.

\section{Recurrent themes definition}

Before embarking on the presentation and critical discussion of relevant literature we introduce and describe a few recurrent terms in this paper. We will use stories to denote the content of books, and books or e-books (to 
include all digital instances based on models inspired by different aspects of the book metaphor, such as purpose, appearance and/or functionalities) to indicate a container of stories. Stories have a plot and a narrative element. Stories for pre-school children are narrated mainly by images with or without text (wordless picture book/story). With collaborative or co-reading we describe a shared book reading experience involving at least one child and one adult. This can take place at home or pre-school, and, accordingly be more or less structured while involving extra activities beyond readings. These may include making voices and acting, posing questions from and to the child and changing the story by adapting it to the child's inclinations, context and needs. With the term digital story we refer to a combination of digital images, text, recorded audio, video and music combined with the purpose of telling a story [10]. Collaborative or co-writing is intended as the production of a new narrative, a joint effort by at least one child and one adult. We refer to collaborative or co-creation as being the full process from inspiration to the production of a story, including writing.

In the following we present a concise literature review about co-reading and collaborative writing research projects and tools.

\section{Literature about co-reading}

Overall, the literature highlights how high levels of participation and engagement can have an impact on children's vocabulary construction and ability to selfexpress. Whitehurst et al. [18] reported a significant increase in the speed at which pre-school children developed language after asking their parents to co-read with them picture books and to follow a procedure devised by authors to favour children's active engagement. This work has since been cited by number of authors, among them more recently Verhallen at al. [17] report on how using animated stories with multimedia additions such as video, sound and music helped in "expanding vocabulary and syntax" even when children were not supported by adults. They also point out how multimedia storybooks could greatly benefit children whose parents, for varied reasons, are not able to share reading and writing with them. Rhodes and Walsh [7] involved children and their low literacy parents in a paper versus electronic book comparison followed by a co-design exercise. The data gathered by observations and interviews were organised as recommendations for the development of new reading technologies: to favour "accuracy and comprehension" over speed, to encourage readers to use actions and voices, and to foster independence and motivation. Richter and Courage [8] compared how children engaged and recalled a story available on a multimedia interactive e-book versus paper. Their findings indicate how the multimedia elements of the e-book made reading more engaging without causing extra cognitive overload or distraction. In terms of recall there was no difference between paper and electronic books possibly because that depended on the story itself. A very close but much more detailed analysis of the impact of interactive animated e-books on language development for children in pre-schools without adult support is to be found in Smeets and Bus [14]. Authors found out that children engaging with the interactive animated e-book gained a higher increase in their vocabulary compared with those in the other groups (who used static and animate books). Finally, educators were encouraged to "... take responsibility in creating a literacy supportive technology environment for young children to design e-books that include effective multimedia and interactive features".

\section{Collaborative digital storytelling tools: a brief review}

Besides the co-reading activities, the collaborative writing of digital stories also supports the development of children's higher cognitive abilities including language, communication and social. In literature, the benefit of children being authors of multimedia digital stories rather than passive consumers [2] is well known. These benefits increase when the digital storytelling becomes a collaborative experience [5]. Recently, the research community has focused on developing a few authoring tools to challenge these research issues. For instance, StoryKit [1] allows children to collaboratively create a story made of photos, audio, text and drawings (no video) through a mobile phone. The story can be shared online on the International Children's Digital Library (ICDL) developed by the same authors. ToonTastic is another tool meant to facilitate the collaborative creation of a story by using a multiple-pen display [13]. StoryMat [14] is based on a play mat that records the children's voices, rumours and oral stories. POGO [9] also offers an enhanced physical environment where children can use different artefacts to create the media contents for their story. Other tools focus more on providing an interactive system that guides children on a workflow to support the collaboration. For instance, Fiabot! [11] supports the creation of multimedia stories in school by actively supporting the interactions with the children and the teachers within the process of creation of the plot, the characters and the media. More recently, within the Q-Tales project, a platform was developed for adults (parents and professionals) to co-create new or transform available children books [16] and share those online.

Despite these works indicating a strong interest in supporting a collaborative experience, none of these are specifically designed for pre-literate children with the purpose of supporting the development of language, communication, and social skills. Our contribution focuses on this area: how to design a user experience for preschoolers to support the co-creation of a story.

In order to understand the possible challenges and to identify future research directions we conducted an explorative study. This pilot aimed at producing concrete evidences that could reveal the opportunities of designing technology to support pre-literacy skills development in 
school. The outcomes will be used to inform the development of an authoring system for pupils in preschool.

\section{THE RESEARCH}

The project has both a theoretical research objective and a design purpose i.e. design an authoring system for preliterate pupils. The research questions are:

1. How can technology help pre-literate children to create a multimedia story?

2. What are the main educational benefits of the experience?

3. How can technology support teachers in running coreading and co-writing activities in preschool?

In order to answer these research questions, we ran a pilot study in a pre-school. In what follows we introduce the school curriculum of the country where this was carried out.

\section{Pre-school curriculum}

The study was conducted in a pre-school in Switzerland with children aged 5-6. According to Piaget's four stages of cognitive development [6] children at this age are at the pre-operational stage (2-7 years old).

Concerning the language development children progressively learn how to use symbols. Pre-reading activities support the logical thought development as children start to realize that words represent ideas, and, in some cases, are connected with actions. Indeed, according with the Swiss curriculum children start pre-school at the age of 3 until they go to primary school at the age of 6 . Pupils are not expected to develop writing and reading skills (which is the purpose of the primary school) but to acquire pre-literate skills. However, the curriculum includes activities for stimulating the development of pre-reading and writing skills, as well as fostering communication skills. Among those are the co-creation and the co-reading of stories. Teachers read the stories from text or image books and children listen. Usually, teachers are very expressive while they are reading; they use different voice tones and emphasize specific words.

Children create stories by drawing characters and other story elements (e.g. a house) and with the help of the teacher, they develop the plot, which is orally expressed. In some cases, the teacher writes the plot, while in others the children act out the story. Every three weeks, teachers establish a specific topic on which they will work within a different subject area. The topic could be a seasonal subject i.e. Christmas. All the activities are focused on this topic including the story reading and authoring.

In what follows we will present the study and introduce the specific school context.

\section{THE PILOT STUDY}

The pilot study's aim was to uncover the challenges and opportunities to design a tool for supporting teachers to conduct activities in school, oriented to pre-reading and pre-writing skills development. The pre-school that took part in our study is public and has in total 3 classes: one with children aged 3-4 (10 children), and two with pupils aged 5-6 (25). There are three teachers and they rotate from one class to the other according to three main subjects: T1 teaches visual literacy and music, T2 arithmetical and digital literacy skills, and T3 communication and language skills. However, the teachers are trained to cover all of the three subjects. All three teachers were involved in the project since the study addressed all of the three different sets of skills. In addition, from a consensus-building perspective, having all the teachers involved was a great advantage. We met the teachers and the school's director two months before the project started in order to agree on the procedure. It was very important to negotiate and refine the research by including the school stakeholders' perspective. Thus, starting from our research questions and interests we refined the research objectives, approach and tasks with the school directors and the teachers. All the parents were informed about the study, and they gave their written consent. Children were not obliged to participate in the study and they could stop taking part in it at any time they wished.

A selection of the older children (aged 5-6) participated in the study. Teachers selected the children according to their proficiency in visual literacy, language, communication, emotional and social skills. In total, we engaged 15 pupils $(\mathrm{M}=\mathrm{n} 7, \mathrm{~F}=\mathrm{n} 8)$. We got a mixed group with pupils who are advanced (3), typically developed (9), as well as some with abilities gaps in the specific topics (3).

\section{METHODOLOGY}

Our research questions and methodological approach are grounded on the theoretical foundation of socioconstructivism [22], as well as how it relates to the children's development. Indeed, we considered how children used technology within the socio-historical context in which the activity took place. In particular, given our previous experience in similar contexts, we chose to use an iPad and three applications selected by researchers as being easy to use for pre-school children.

The study was run following the participatory design [20] approach and involving the stakeholders (both adults and children) as informants [3]. The nature of our research questions suggested an explorative approach. Thus, in order to find the answers, we embraced a qualitative approach based on contextual interviews (teachers), observations (of class activities), and focus groups (children and teachers). Each data set was analysed separately. The transcriptions were elaborated by using both induction, and deduction methods. Researchers combined the emerging themes in order to answer the main research questions. We also analysed the story and the multimedia content created in order to understand the type of media used and how children narrated the story by using these. The teachers 
helped us in making sense of the story and understanding how children created the media with the purposes of representing the story chapters.

We articulated the pilot study in three main phases:

1. Activity analysis, and plot creation;

2. Children training in using the device for multimedia content creation, introduction to the tool, and its use in class;

3. Organization of the media for the creation of the story, reflection on the experience, and collection of feedback from children and teachers.

In what follows we present the different phases of the project, the activities in which the intervention was articulated and the outcomes.

\section{Project phases}

We organized the pilot study in 3 stages, 9 activities within a period of 2 months. Each activity lasted one hour and was run at school, mainly by the teachers supported by the researcher. In what follows we provide a brief description of the project phases.

Phase1. Activity analysis, and plot creation.

The researchers explored how the activity was run in class before the intervention.

Activity 1. Researchers interviewed the teachers and observed the activity in class. This stage aimed at making the researchers familiar with the context as well as to introduce them to the school environment and the children. The researchers have been working for several years with children, however each context has its peculiarities. The teachers started to introduce in class the activity for the following week: creating a story. They also introduced the researchers to the children.

Activity 2. The teacher presented the children with the structure of a story and its main components (characters, animals, places, objects, means of transport, and the problem to solve) and asked them to make three drawings for each of them by using paper and crayons. Children worked in teams of two organized by the teachers according to the children's abilities and social attitude in order to create a collaborative environment. At the end of the lesson children selected the drawings that would be later used for the story.

Activity 3. The teacher and children, inspired by the drawings, started to co-create the story plot. As in other activities run in class the teacher stimulated and orchestrated the brainstorming with the children. The teacher later transcribed the plot of the story.

At this point researchers had a better understanding of the context, and children had got used to their presence. The main outcome of this phase was the complete plot of the story being ready for Phase 2.
Phase2. Training in using the device for media creation, Introduction to the tool, and its use in class.

We introduced technology within the class activity in order to explore the opportunities and challenges within this context.

Activity 4. The researcher introduced the iPad to the children and started to teach them how to make drawings by using a simple application selected by researchers. Children were grouped in pairs. At the end of the lesson many drawings were created.

Activity 5 . The same procedure of activity 4 was applied to teach the creation of sound with an equally easy to use suitable application.

Activity 6 . The same procedure of activity 4 was followed for teaching how to take a photo, and again an intuitive application was proposed by researchers.

As an outcome of this phase, children got familiar with three different applications and produced a lot of multimedia material ready to be organized according to the plot of the story as produced by Phase 1 .

Phase3. Organization of the media for the creation of the story, reflection on the experience, and collection of feedback from children and teachers.

Activity 7. Children were assigned to a specific part of the story, and with the researchers they organised the media produced within the story's structure. Each pair was also questioned by the researchers regarding the best and the worst aspects of the experience.

Activity 8. Media organisation with the teachers, and overall refinement of the story.

Activity 9. Collecting feedback from children through a general discussion (focus group), and conducting a deep interview with the teachers.

The complete story was then presented to the parents in a plenary session.

\section{The story}

The story produced was made of multimedia and no text, with the exception of a picture of the handwriting of one of the children who was very proud of her writing skills. At the end of Phase 2, children created 36 audio files, 83 images, and 14 videos. These were displayed on a big screen and selected by children with the help of the teachers and the researcher. At the end of the selection just some of the media were used for the story. Those were organised in 8 chapters: the parts of the story. These parts were not balanced in terms of number of media according with the type. For instance, chapter 6 (see figure 1 left) has 1 image, 2 videos and 7 audios, chapter 5 (see figure 1 right) has 3 audios and 3 images, and no video. 




Figure 1 Two screenshots of the story, chapter 6 on the left and chapter 5 on the right.

In the following we report the evidence that emerged from the data analysis organised according to the three main research questions. During the analysis, we anonymised the data: T1, T2 and T3 to indicate the teachers, and IDn to indicate the children. In the paper, we reported some quotations as evidence by using brackets and italics.

\section{RQ1: HOW CAN TECHNOLOGY HELP PRE-LITERATE} CHILDREN TO CREATE A MULTIMEDIA STORY?

In order to answer this question, we used data collected from the teachers' interviews, observations and the feedback provided by the children.

\section{The use of media}

Overall, teachers were impressed by the quick learning curve of children in using the iPad and the three applications introduced in Phase2, as well as how they were able to produce very "nice" pieces of media for the story. Drawings and audio were the two main media used $(89 \%)$ probably because the activity in class is usually based on visual and audio input as suggested by T1: "drawing and listening are the two main communication channels in preschool class. Thus, the pilot was quite successful from our perspective since it helped to reinforce the abilities connected with these activities." The teachers were quite surprised about how children used media in a creative way: "Video were not used much, however those produced were quite interesting. They shot videos with a still image and sound in the background. It was like a talking image" T1.
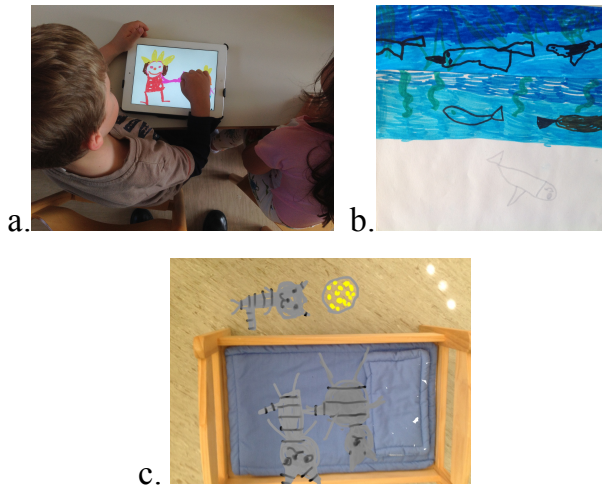

Figure 2 Drawings made with (a) and without iPad (b)- and picture-drawings (c).

Indeed, drawings were the main media produced $(62 \%)$ in different forms: hand sketches - made with (see figure 2 a) and without iPad (see figure $2 \mathrm{~b}$ ) -, and picture-drawings - a picture with hand drawing on top of it (see figure $2 \mathrm{c}$ ).
This preference was due by the fact that "making drawings it was more immediate for them", T3. In particular, children really enjoyed taking pictures and painting on top of it (picture drawings $\mathrm{c}$ in figure 2). Teachers found these kinds of drawings very effective "the narrative was enriched by these picture-drawings that resulted in being very immediate and highly communicative in terms of conveying the story" $\mathrm{T} 2$.

However, the main drive for storytelling and the most engaging media for the authors was the audio. T1: "listening to the audio makes the story more engaging and it helped achieve a better understanding of the plot. Children gave their recorded voices to the characters. This made authoring a very engaging activity for us as well as for the children. They became part of the story themselves" T2; "I found the dramatization of the story by using the audio very interesting. It was very effective." Nevertheless, even if recording audio was quite engaging for children, it also required some extra effort compared to the creation of images. T3: "Extra effort is required for planning recordings properly. This is because children have to decide in advance what to say before they start recording ". Actually, according to the teachers this is the main reason why the video was less used by pupils $(11 \%$ out of the total media produced). T3: "Children ended up producing and using fewer videos as they need to think about what to say and do in advance. This implies the need for forward thinking and planning. Drawing instead is a more spontaneous activity, children can just get an iPad and draw." "A video describes an action and as such it requires more planning while a drawing or a dialogue are more spontaneous in nature. Both describe a specific moment."

\section{Children's perspective}

Despite drawing being the medium more used, children mentioned some difficulties in using the iPad. For instance, ID5 "when I tried to draw a line using my finger it didn't appeared immediately". Or ID10 "The trace I made using my fingers was ugly. I could make it better with the pencil". According with the teacher T2: "Maybe some of the children did not enjoy drawing with their fingers as it did not allow for precision in tracing. " From the interviews, it emerged that children's preferred activity was recording the audio. They really enjoyed acting as the story's characters: it allowed them to be the characters. ID3 "I want to play the role of Giovannino". This is confirmed also from the data we collected during the observation in class where children spent a lot of time in recording audio individually and in pairs. Looking at the audio produced they also created a lot of ambient sound recordings e.g. sea waves or cats meowing.

\section{Children understanding of the overall story.}

The story plot was created collectively by the children who were coordinated by the teacher. After this main step, children were asked to create media in pairs by using the iPad and the applications they had learned to use in Phase2. 
Each group worked separately on a specific piece of the story as assigned by the teacher. From that moment, it seems that children were more focused on their part and they lost a bit the overview of the overall story. T3: "the story was assembled by the researcher and the children together. However, it was the researcher who drove mainly the activity. The children were more passive in this task and they didn't achieve a complete understanding of the overall story. They are used to books that have a beginning and an end, so building just a piece of the story didn't provide them with the sense of the overall plot." We have to mention that at the time of the interview children didn't see the whole story, indeed this happened a few days later. However, it was relevant to report this issue for future design purposes.

Indeed, for children it was very difficult to use the application for combining the media, T1: "The researchers needed to support the pupils from a technical point of view, they knew how to put the media together but technically it was too difficult for them. I expected them to show a limit in the usage of technology so I wasn 't really surprised"

\section{Children perspective}

During the interviews, it became clear that children did not have a full picture of the story produced. When we asked them to tell us about the story they just created they were able to tell us just their specific part. ID2 "Giovannino did a lot of sport". ID4 "the queen and the king have three cats". ID10 "the boat was almost sinking with the king and the queen, but Giovannino rescued them".

\section{Summing up}

Summarising these outcomes, the answer to RQ1 is that the use of pre-selected applications on the chosen device helped pre-literate children to learn how to create media such as drawings, picture-drawings, audio and video in a way that children can express themselves as never before. From the data, it emerged that children quickly learned how to creatively use the different media opportunities (e.g. using the sound to interpreted the characters), however they had a limit in combining the different pieces in the whole story and they missed out on the overall understanding. Thus, it seems that children can easily get a basic understanding of how to use the technology but they struggle with the most conceptual aspects of creating a story. However, this is in line with the pre-operational stage of typically developed children.

\section{RQ2: WHAT ARE THE MAIN EDUCATIONAL BENEFITS OF THE EXPERIENCE?}

This research question concerns mainly how the creation of digital stories supports the development of children's skills included in the curriculum. We mainly looked at the teachers' feedback to answer this question. Teachers have a rubric to assess children at the beginning, during and at the end of the school year. The rubric is defined in the Swiss curriculum and it includes 9 main elements: emotional wellbeing, self-awareness, social interaction, selfdirectness, understanding of context, communication, logical thinking, physical manipulation, and physical awareness. Teachers noticed an overall improvement in the children's cognitive and social skills concerning several aspects as in their rubric. Following, we present the main issues emerged from data analysis organized by four main themes, each of them supported by relevant elements from the grid:

1. engagement and motivation,

2. peer interaction and social behavior,

3. emotional development,

4. communication and self-expression.

\section{Engagement and motivation.}

The activity of creating digital stories has a positive impact on improving self-directness. By engaging and motivating children in performing their tasks and achieve their objectives. Teachers reported that children during this activity stayed focused for a longer period of time than usual and this impacted on their ability of managing and carrying out the activities proposed. T2: "the attention on an activity was much longer than during a typical activity. Children were very focused on what they were doing." T1: "Pupils usually didn't concentrate for a long period of time on a task, however in the creation of media they were engaged and more focused on a specific task". Another important limit that they overcame was to accomplish the task properly. Through this activity children trained their logical thinking. As T3 mentioned "for children to meet the delivery requirements was a big challenge both in terms of contents and timing. Indeed, it was quite interesting to notice how they evaluated and choose the different options for representing the story".

\section{Peer interaction and social behavior.}

As the previous study showed [11] one of the main issues in these kinds of activities is to support children's collaboration in performing a task. Children were grouped in teams of two. The pairs were made by the teachers according to their skills, and considering their emotional, and social attitude. The collaboration was very difficult and often the teachers' intervention was to ensure proper turntaking and that the children with dominant behaviour did not take the control of the device, T2: "It was very difficult for children to work in pairs. In terms of pursuing a common goal, planning the activity, and sharing the resources. For instance, they couldn't work on the iPad together for making a drawing they had to negotiate who would use it first". Indeed, the turn-taking required by the hardware was important to train them in negotiating and communicating their ideas and needs T1: "to train them in respecting the turn taking was important to support the social skills... the improvement in collaboration was very effective and emerged quite soon". In addition, the use of a unique artefact in the group and the need of sharing the resource pushed children to challenge their social interaction skills as well as improved their self-awareness. Teachers reported that, not surprisingly, the collaboration 
was very difficult and often they intervened to ensure proper turn-taking. In particular, T2: "It was very difficult for children to work in pairs. In terms of pursuing a common goal, planning the activity, and sharing the resources..."

\section{Emotional development.}

Children challenged their limits and boundaries: they followed the teachers' instructions and the researchers' suggestions while creatively performing the task. In addition, some of those who were shyer or have emotional issues demonstrated a great improvement in selfexpression. T1 "overall I have noticed that children who were shy used the technology to open up themselves. They didn't feel any discomfort or frustration in creating audio by using their voices. It was a great benefit for them to perceive the technology as an opportunity for expressing themselves. They felt free from being judged. These activities helped them to break the emotional boundaries that sometimes there are in school". It seems that this activity reduced anxiety and helped children to overcome the pressure felt in performing the action properly without making errors. T1 "some children are usually quite anxious and they are afraid to act in a wrong way. When using these applications they were not afraid of being wrong since they could recover easily from the error and redo the task. Also in front of the teachers they were not afraid of being wrong. They could always cancel and redo the drawing or the audio. Thus, children didn't feel the pressure of being right".

\section{Communication and self-expression.}

Teachers were surprised to see children with communication and language problems able to easily record their voices. T2: "there are few children who cannot speak correctly our language because they have just arrived from foreign countries or because they have language-related communication difficulties. Those pupils created a lot of audio files". Moreover, some shy children could express themself and participate to the class activity. T1: "I have seen children that usually have hard time in talking because they are shy to register their voice and use it as a character voice." In addition, also the children who never used any interactive devices learnt quite easily how to physically engage with it and how to use the iPad to express themselves. T3: "I thought they might have some problem in handling the device, especially for the youngest. However, it wasn't an issue for them, at all. For instance, the will of using it to create video pushed them to learn how to handle it also physically".

\section{Summing up}

In order to answer to RQ2 we use as reference the teachers' rubric that they use over the year to assess the children improvement. Thus, our understanding of the potential benefit of this intervention from a pedagogical perspective is based on the teachers' assessment. Indeed, from the data analysed, the answer to RQ2 is that our intervention in school had a positive impact on the reduction of performance-related stress, the increase in attention, the training of children in overcoming individuality and acting more collaboratively, the development of their emotional and social skills, as well as their improvement in communication and language abilities. All these aspects contribute to reinforce the children's cognitive development.

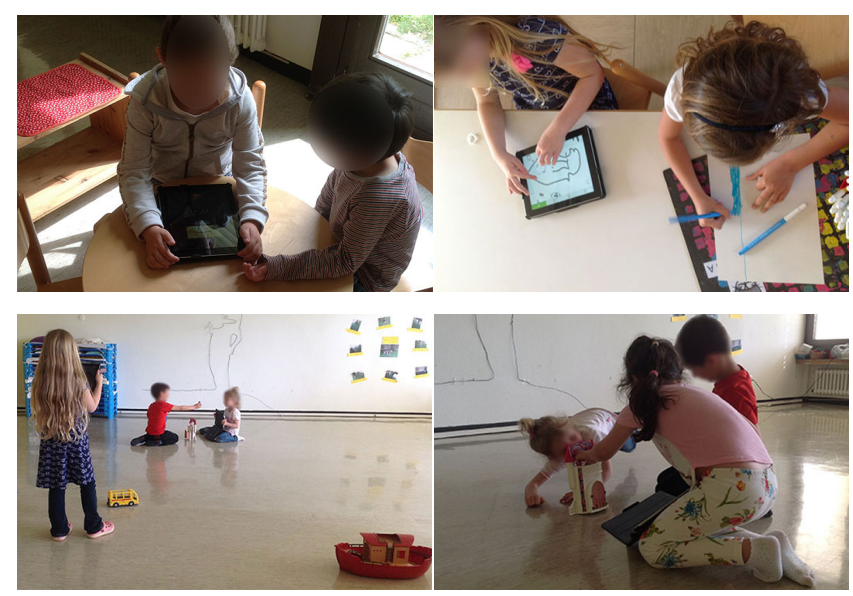

Figure 3 Children working to gather in creating the media.

\section{RQ3: HOW CAN TECHNOLOGY SUPPORT TEACHERS IN RUNNING CO-READING AND CO-WRITING ACTIVITIES IN PRE-SCHOOL?}

The last question is related to the teachers' activities and abilities to integrate technology within the context of the lesson. Thus, during the interviews we explicitly asked the teachers to reflect on the role of technology in class, and whether this experience affected their teaching in future.

First of all, they mentioned how the use of the iPad inspired the activity in class and how the opportunity offered by the applications allowed them to envision other possible usages. T2: "For instance, it was inspiring to see children drawing on top of a photo, children enjoyed this activity very much. It was a new thing, we have never done it before, and perhaps we would have never done if it was not for this opportunity." T1: "The presence of an iPad in class has introduced a novel modality of expression." Moreover, children themselves suggested using the iPad for other activities such as recording a message describing a different project. T2: "Children who participated in the study are independent in its usage and became experts. I am using my iPad to run other activities where more expert children will be teaching younger ones how to use it." Teachers and researchers co-worked in the project with different roles connected with their specific domain knowledge as well as with the different stages of the process. Teachers acted mainly as facilitators: they stimulated the discussion during the plot development and gave suggestion on children media development. T2: "Children had a very clear idea of what we were doing. My role was to provide suggestions mostly on content." Despite children being quite autonomous, both teachers and researchers provided important support in terms of giving an overview of the 
workflow as well as of the story plot. T2: "Even if, children have planned and prepared all material to build the story, the story composition and the media ideation sometimes was performed together with their teacher." This challenging activity helped the teachers to understand better how far pupils could be stretched to. T1: "For us too it has been a learning process. Not only because we have discovered how competent children already were but also because we have realised the potential of this new tool in teaching".

In addition, they recognised the important value of the researcher's role in supporting the development of the activities. T1: "Researchers have played a crucial role in organising and polishing the story in its final version as this was too hard for children to do by themselves."

\section{Summing up}

When considering computer technology at large, the answer to RQ3 is that, not surprisingly, teachers saw a lot of benefits in its introduction in pre-school. They appreciated its potential as an inspiration for teaching different subjects, and for creating a very positive collaborative atmosphere with their pupils. Teachers were amazed by the level of competence of their pupils and how independent they quickly became in using the various applications. By examining the teachers' comments on the role played by researchers it becomes clear how, given their levels of expertise, children effectively became editors and publishers of the story.

\section{EMERGING CHALLENGES AND POSSIBLE DESIGN DIRECTIONS}

The iPad and the applications running on it had an overall positive impact on the proposed activity. Thus, by considering the outcomes of this pilot study, we elaborated a set of emerging challenges, and possible design directions:

1. Turn taking and collaborative activities,

2. Assisting editing and publishing to support autonomy,

3. Supporting the overall understanding of the story,

4. Predefined toolset for media mix.

These 4 challenges aim at informing the design process of an authoring tool to support pre-literate children, and their teachers, in the creation and production of multimedia stories in a school context.

\section{Turn Taking and collaborative Activities.}

The authoring tool will have to support and facilitate adults and children when collaboratively creating new stories. It should support different forms of collaboration among children and with adults. Particular attention has to be paid on sharing tasks. Indeed, in our study this emerged as being critical, T2: "It was very difficult for children to work in pairs... For instance, they couldn't work on the iPad together for making a drawing they had to negotiate who would use it first". Besides, the tool will need to enable users to set the type of desired collaboration with an adult who is acting as facilitator: from light to heavily engaged. For instance, the adult would be less involved in tasks that proved to be easy and engaging for children such as drawing or recording sound. As reported by T3: "making drawings it was more immediate for them, as well as recording sounds".

On the other hand, other tasks that implied a more thoughtful plan required stronger support from adults. Such as preparing a dialogue or making videos. T3: "Children ended up producing fewer videos as they need to think about what to say and do in advance. This implies the need for forward thinking and planning." Also, the turn taking in using the device sometimes required the presence of an adults, T1 "Sometimes I have noticed that one child took the ownership on the use of the device. I needed to intervene in order to make them aware that the device has to be used equally by all the member of the group". In addition, the new tool should assist the children technically through all the steps of the process, from the creation of the plot to the acquisition of multimedia material, with the composition, and the publishing of the story. Ideally, it should substitute the researchers acting as editors and publishers as reported by T1 "The researchers needed to support the pupils from a technical point of view..." and T3: "the story was assembled by the researcher and the children together. However, it was the researcher who drove mainly the activity."

While teachers are expected to keep providing help and support on content production, the new authoring tool will have to provide the technical scaffolding to enable children to work as comfortably as they did when they knew researchers would be there to fix and solve any practical problems.

The new tool needs to provide tips and support, be simple, and allow for easy recovery from common mistakes such as: deleting a drawing by mistake or painting on top of somebody else's art work. Both events occurred very often during our observations and caused lot of drama T2 "Sometimes children lost their drawings because they forgot to save these. Or the drawings were modified by other children and they were not able to recover their original ones. Since this task required a lot of effort, if the media they created disappear this could be very painful for them and the cause of drama".

\section{Supporting the overall understanding of the story}

The tool should allow the creation of short stories: as emerged from our study, children at this age can hardly create a long and articulated story. The three teachers agreed that children can remember and elaborate just a specific part of the story "the story created in class was divided in several parts because the children could not remember it as whole" $\mathrm{T} 2$.

The new tool needs to assist them in getting an overview of the story as well as of its individual chapters or sections. 
"Children during the activity in class didn't achieve a complete understanding of the overall story" T3. This was confirmed also from the data collected by researcher interviewing the children..

\section{Predefined toolset for media mix}

The authoring tool should provide a number of pre-selected sets of functionalities (or applications as in our study) to be used in the creation of media and for mixed-media e.g. pictures with drawings or sketches with sound. T1 "children really enjoyed creating images and sounds but sometimes they were limited in «making the characters speak»." Considering the same type of task, the graphic user interface should be suitable for the cognitive and physical development of such young users. T2: "Children found it very difficult to jump from one tool to another. The use of separate applications for media creation caused a cognitive overload." In addition, the system should allow them to create different types of audio recordings and edit them separately as well as combining those with pictures or any other content. T1: "children enjoyed recording their voices as character voices, noise, ambient and animal sounds. They used recordings in many different ways".

These challenges are relevant to the design of any authoring tool (audio story, wordless picture books, picture book with words etc.) for pre-schoolers, and to the development of user interface for educational tools targeting this specific age group.

\section{CONCLUSION}

Literature indicates that pre-literate children can find a benefit in co-reading and co-creating stories with adults [18], with their peers [14]. Indeed, the use of technology can amplify this experience and provide a concrete support in the development of language and communication skills [4]. In our explorative study, we considered this activity in a formal educational context, and the opportunities and challenges of designing an authoring tool for narrative skills development. The emerging challenges are described in order to inform the design process towards the implementation of a working prototype to be tested in preschools. Other research projects addressed similar issues. For instance, Q-Tales [16] focuses on the co-creation of narrative stories with an educational flavour but outside the school environment. Indeed, designing for and with schools' stakeholders has many specific constraints as well as opportunities. The results of our study are somewhat limited by the small sample of subjects included and the curriculum, which is specific to this European country, Switzerland.

\section{Future work}

A number of open issues still need to be solved by following studies with children, teachers, and design experts.

The next step would be to produce a prototype (following a participatory design approach) and test it in different contexts, both cultural and curriculum-wise. In addition, other researchers in the field could use these lessons learned to inform their work in a related context. Indeed, we plan to properly document and formalise this methodological approach in order to allow members of the community to apply it in other contexts.

\section{ACKNOWLEDGMENTS}

We thank all the people involved in the project, especially the Vezia school's director who was very supportive and allowed us to conduct the study. The wonderful teachers Michela Aili Skory, Claudia Bertoldi Simaz and Barbara Salerno for their professionality and enthusiasm, without them the study would not be so successful. Indeed, our special gratitude goes to the wonderful children who worked with us, we learnt a lot from them and we had lot of fun! Finally, a special acknowledge to our colleague Emma Nicol who did the proof reading and provided useful feedback and insights during the writing.

\section{REFERENCES}

1. Bonsignore E, Quinn AJ, Druin A, Bederson BB. Sharing stories "in the wild": A mobile storytelling case study using StoryKit. ACM Transactions on Computer-Human Interaction (TOCHI). 2013 Jul $1 ; 20(3): 18$.

2. Iurgel, I.A., Zagalo, N. and Petta, P. (Eds.) Proceedings of ICIDS (International Conference on Interactive Digital Storytelling) 2009, 9-11 December, Guimarães, Portugal.

3. Ole Sejer Iversen, Rachel Charlotte Smith, and Christian Dindler. 2017. Child as Protagonist: Expanding the Role of Children in Participatory Design. In Proceedings of the 2017 Conference on Interaction Design and Children (IDC '17). ACM, New York, NY, USA, 27-37. DOI: https://doi.org/10.1145/3078072.3079725

4. Ofra Korat. 2010. Reading electronic books as a support for vocabulary, story comprehension and word reading in kindergarten and first grade. Comput. Educ. 55, 1 (August 2010), 24-31. DOI=http://dx.doi.org/10.1016/j.compedu.2009.11.014

5. Ali Mazalek, and Glorianna Davenport. "A tangible platform for documenting experiences and sharing multimedia stories." In Proceedings of the 2003 ACM SIGMM workshop on Experiential telepresence, pp. 105-109. ACM, 2003.

6. Jean Piaget. 1964. Part I: Cognitive development in children: Piaget development and learning. Journal of research in science teaching, 2(3), pp.176-186

7. Emily Rhodes and Greg Walsh. 2016. Recommendations for Developing Technologies that Encourage Reading Practices Among Children in Families with Low-literate Adults. IDC '16: Proceedings of the 15th International Conference on Interaction Design and Children. 125-136 
8. Anna Richter and Mary L. Courage. 2017. Comparing electronic and paper storybooks for preschoolers: Attention, engagement, and recall. Journal of Applied Developmental Psychology 48. 92-102

9. Antonio Rizzo, Marti Patrizia, Decortis Françoise, Rutgers Job, and Paul Thursfield. "Building narrative experiences for children through real time media manipulation: POGO World." In Funology, pp. 189199. Springer Netherlands, 2003.

10. Bernard Robin. "The educational uses of digital storytelling." Technology and teacher education annual 1 (2006): 709.

11. Elisa Rubegni and Monica Landoni. 2014. Fiabot!: design and evaluation of a mobile storytelling application for schools. In Proceedings of the 2014 conference on Interaction design and children (IDC '14). ACM, New York, NY, USA, 165-174. DOI: http://dx.doi.org/10.1145/2593968.2593979

12. Elisa Rubegni and Monica Landoni. 2015. Supporting creativity in designing story authoring tools. In Proceedings of the 14th International Conference on Interaction Design and Children (IDC '15). ACM, New York, NY, USA, 287-290

13. Andy Russell. 2010. ToonTastic: a global storytelling network for kids, by kids. In Proceedings of the fourth international conference on Tangible, embedded, and embodied interaction (TEI '10). ACM, New York, NY, USA, 271-274. DOI=http://dx.doi.org/10.1145/1709886.1709942

14. Kimiko Ryokai and Justine Cassell. 1998. StoryMat: a play space with narrative memories. In Proceedings of the 4th international conference on Intelligent user interfaces (IUI '99). ACM, New York, NY, USA, 201-. DOI: https://doi.org/10.1145/291080.291126

15. Daisy JH Smeets, and Adriana G. Bus. "The interactive animated e-book as a word learning device for kindergartners." Applied Psycholinguistics 36.4 (2015): 899-920.

16. Doukoulos Theodoros, Chita Murray, Michael Hogan, Owen Harney, Tony Hall, and Bonnie Thompson Long. 2017. Using a Collective Intelligence ScenarioBased Design approach to develop a collaboration ecosystem supporting the authorship of pedagogically valuable e-books for children. The Journal of Literacy and Technology Volume 18, Number 2: Summer/Fall 2017

17. Marian JAJ Verhallen, Adriana G. Bus, and Maria T. de Jong. "The promise of multimedia stories for kindergarten children at risk." Journal of educational psychology 98.2 (2006): 410.

18. Greg Walsh, Allison Druin, Mona Leigh Guha, Elizabeth Bonsignore, Elizabeth Foss, Jason C. Yip, Evan Golub, Tamara Clegg, Quincy Brown, Robin
Brewer, Asmi Joshi, and Richelle Brown. 2012. DisCo: a co-design online tool for asynchronous distributed child and adult design partners. In Proceedings of the 11th International Conference on Interaction Design and Children (IDC '12). ACM, New York, NY, USA, 11-19.

19. Grover J. Whitehurst, Francine L. Falco, Christopher J. Lonigan, Janet E. Fischel, Barbara D. DeBaryshe, Marta C. Valdez-Menchaca, and Marie Caulfield. "Accelerating language development through picture book reading." Developmental psychology 24, no. 4 (1988): 552.

20. Schuler, Douglas, and Aki Namioka. 1993. Participatory Design: Principles and Practices, L. Erlbaum.

21. Vygotsky, Lev Semenovich. (2004; 1967). Imagination and creativity in childhood. Journal of Russian and east European psychology. Vol 42, no. 1

22. Vygotsky, Lev Semenovich. (1978) Mind in Society: The Development of Higher Psychological Processes. Cambridge, MA: Harvard University Press 